\title{
Research on the Relationship between e-commerce and Chain Business (Taking China as an Example)
}

\author{
Pingli $\mathrm{Li}^{*}$ \\ No. 65, Xueyuan Street, Chengdu, Sichuan, China, School of Economics Management Sichuan Technology and Business \\ University \\ "Corresponding author
}

\begin{abstract}
Global e-commerce has made breakthroughs in information technology, making people's business ideas and ideas with new concepts and transformations. At the same time, with the development of the economy, the importance of the retail industry has become greater and greater. The advantage of shackle management lies in economies of scale, and the economies of scale are not only How much is the amount of money, and more importantly, whether the shackle enterprise realizes lowcost operation and high commodity turnover. The clarity and completeness of the rate, function, the improvement of the management system and the increase in the size of the singlehanded goods. E-commerce has important benefits for improving the competitiveness of shackles retail enterprises. This paper discusses the mode of collaborative operation between ecommerce and shackle management, and analyzes the basis of its collaboration.
\end{abstract}

Keywords—shackle management; global e-commerce; supply chain strategy

\section{INTRODUCTION}

The shackle operation is a form of retail. The world retail industry has experienced three revolutions, the first is the emergence of retail stores; the second is the rise of supermarkets and supermarkets; the third is the emergence of the shackle shop, which conforms to the society. The trend of chemical production has created a broader space for the circulation of goods. Shack lock business and super. The market is known as the great symbol of the "modern circulation revolution." After the mid-20th century, modern shackle operations have achieved widespread success in developed countries. Wal-Mart, the world's largest commercial retailer, sold sales totaling $\$ 191.3$ billion in 2000, surpassing that of General Motors. A retail enterprise belonging to the traditional industry.

In the auto industry, which can surpass the "king of manufacturing" in sales revenue, more than some large banks, insurance companies and other financial institutions, more than the information enterprises that cited the "new economy", one of the key factors is the development of shackles. From the international experience, the guidance and promotion of commodity circulation to production is getting bigger and bigger. It is impossible for a country with economic and social systems to have modern large-scale production without modern circulation. In the process of establishing a market economy, commodity circulation should be placed in a more important position to accelerate the development of shackles.

The shackle operation, especially the franchise method, enables the capital to be quickly concentrated and easy to seize market opportunities; the shackle operation can improve the degree of organization and enhance the market competitiveness; the management efficiency is high, the operating cost is low; the product sales ability is strong, Service advantage; enable enterprises to enjoy the economic benefits of economies of scale. The important development trends of the 21 st century market economy are knowledge, networking, niche, virtualization, innovation, and globalization. In this macroeconomic environment, the organizational form and business format of the circulation industry are taking place.

This paper mainly starts from the characteristics and connotation of shackle management, and discusses the needs of shackle operation and e-commerce. Features, as well as the necessity of shackle management to achieve e-commerce. Then, by analyzing shackles and e-commerce. The connotation of the business, summed up the relationship between shackle management and e-commerce, in order to find out the bottlenecks affecting its development. In order to have a better integration model between shackle management and ecommerce.

The significance of research included: (1) System analysis: E-commerce is a social system engineering that involves the external environment and e-commerce of e-commerce applications. The internal conditions of the application and so on. Therefore, e-commerce application research must rely on the science category. (2) System analysis method Comparative analysis. There are significant differences and characteristics in the shackle management and e-commerce in their respective aspects. The difference and the essence of the connotation, find out the differences, seek solutions, and propose effective business strategies for the deaf.

\section{RESEARCH METHODS}

The three principles of shackle management can be referred to as "3S", namely, simplification, standardization, and specialization. 


\section{A. Simplification}

It means creating conditions that allow anyone to easily and quickly become familiar with the job in order to maintain the prescribed work. Take retail stores as an example. On weekdays, customers spend more time on stores, and holidays are more concentrated. Therefore, in terms of employing people, the store involves the problem of how to rationally allocate and reduce costs. The general practice is necessary

The time period is hired. As a result, a timekeeping management system was created in the store. However, it is impossible to operate for a long time, so it is necessary to simplify the contents of the work in the store, so that the staff who work in the first store only need to add a little. With the exegesis, you can quickly become familiar with the content of the work and meet the job requirements. (N. Dholakia 2016) For the store, the employment of the squatter can pay a lot less than the cost of the skilled worker, thus achieving the effect of employing people and operating at a low cost.

Complex operations are difficult to master in a short period of time. Increasing the time of bad habits increases the cost. The most effective way to solve this problem is to simplify the operation. Emphasizing simplification does not mean reducing operations, because it is difficult to form a system by saving basic operations. Therefore, simplification can completely eliminate the waste department. Points, excess parts, and discomfort parts are used to improve work efficiency.

\section{B. Standardization}

It refers to a reasonable and ideal state of affairs and conditions for the continuous production and sale of products of the expected quality, as well as a business system that can operate in opposition. In general, it is easier to set the specifications for the best quality products, but there are few companies that can always ensure the continuous production and sale of the best quality products.

Because the requirements of the work process, work method, and working conditions are too high, it is difficult for the operator to always comply, and the worker has no problem how to work hard, and cannot produce or sell the product of the expected quality. Therefore, as a shackle operation, when standardization is carried out, it is necessary to ensure that the working process, working method, and working conditions can be executable continuously, (E.S. Harris 2015) the operator can carry out continuous work according to this operating standard. In this way, it is possible to provide customers with products of a desired quality, and to provide goods within a standard time, thereby reducing the waiting time of customers, reducing manufacturing costs and sales costs, and accelerating the flow of passengers.

In the process of construction and development of the shackle network, standardization is very important. For example, when all the systems such as the size, structure, service standards and functions of the store are standardized, the staff of different stores can transfer to other stores and can basically be free from any impact, without any obstacles, is conducive to the rapid development of work. Enterprises that adopt shackles need to set more desirable and higher standards. In order to meet these requirements, companies must carry out training and training. Once the shackle store (or franchise store) meets the standardization requirements, it will leave consumers with the "small shackles of the shackle company."

Good impression of goods and services. Standardization is beneficial to the location of shops in the shackle company, making the opening of the store simple and shortening the construction time of the store. In addition, through the company's unified ordering of machinery, equipment, etc., you can reduce costs and reduce equipment investment in each store. Capital, and thus accelerate the formation of the shackles. In the international arena, enterprises that adopt shackles management attach great importance to the standard level and applicability. After setting the standards, they are constantly revised and adjusted according to the actual situation, and at the same time strive to overcome personal arbitrariness. Modify to prevent the fragmentation of the standardization system. Therefore, the standard formulation and revision of shackles must rely on small expert groups or organizations.

\section{Specialization (also Known as Expertization)}

It refers to the shackle company in order to pursue excellence in a certain aspect, to define the work, and further enhance the competitiveness and development to create unique skills and systems. In the fierce market competition, companies must have their own unique characteristics, and they must be concentrated in a certain. (J. Saastamoinen 2015) A domain and efforts to prevent it from being imitated by other companies requires specialization or specialization.

\section{FEATURES AND ANALYSIS OF E-COMMERCE OPERATIONS}

The biggest characteristic of the shackle operation is to apply the principle of modern production to the circulation area, and bring the scale economic benefits to the enterprise through the standardization, specialization and simplification of commercial activities. The shackle business can pass the group purchasing reduces operating costs, and can also improve management efficiency by exporting standardized management models in many stores to achieve management technology sharing. This can also be obtained from the successful experience of large foreign commercial retail companies.

Fully verified. In 1999, in the list of Fortune 500 companies listed by Fortune, Wal-Mart's sales in 1998 became the fourth largest company in the world with the US\$139.3 billion, the third largest company in the United States. In 2001, Wal-Mart's total sales will exceed US\$220 billion and will soon become the world's top 500. Wal-Mart therefore, the achievement of such remarkable achievements depends on its more than 4,000 shackles stores all over the United States and around the world. Its successful experience is enough to serve as a model for Chinese business enterprises. (T.P. Hoffman 2016) The shackle enterprise is characterized by scale, standardization and standardization. Its management and management characteristics are concentrated in 4 "unified":

\section{A. Unified Image Design}

The image has always been one of the basic characteristics of the shackle enterprise. The image design of the shackle 
enterprise is the responsibility of the franchise center. The image design includes the name of the franchise branch, the mascot used, and the construction of the store. Building style, building materials used, interior decoration, store color, store structure in the store, product identification, trademarks used in goods, salesperson clothing, etc.

\section{B. Unified Market Strategy}

The market strategy is formulated by the affiliate center. Once established, it becomes the market strategy that the entire franchise system follows. Each franchise center attaches great importance to the study of market strategy. When researching the market strategy, fully analyze market opportunities, service objects, own advantages and competitors. On the basis of full evidence, segment the market, determine market goals, and establish market strategies.

\section{Unified Logistics Management}

The main purpose of implementing the shackle system is to achieve economies of scale. The logistics management of the German shackle enterprise franchise center is very strict. Which goods and business varieties are franchised by the franchise branch must be purchased by the center. When each franchise branch needs to purchase goods, it only needs to apply to the center in advance. After the center summarizes the same quantity of goods, the center will notify the supplier to deliver the goods, and the supplier will directly send it to the branch according to the quantity and time of the reservation.

\section{Unified Price Management}

In many franchise systems, price management rights are concentrated in the franchise center. Join each the goods handled by the branch are uniformly purchased by the center, and the purchase price is determined by the center and the supplier. After the franchise center purchases the goods, it is generally supplied to the branch according to the purchase price plus the central interest. The price of each commodity is determined by the center, and the price is clearly priced. The branch generally has no right to float. In the region, the center determines a certain regional difference. (L Exchange 2017) The prices of goods operated by branches in the same region (city) and the same franchise system are basically the same.

\section{SURVEY RESULTS}

As part of the research, we sent out email surveys to help clients with the primary and secondary goals of research. A convenient sample of the basic filter contains the following (see Figure 1):

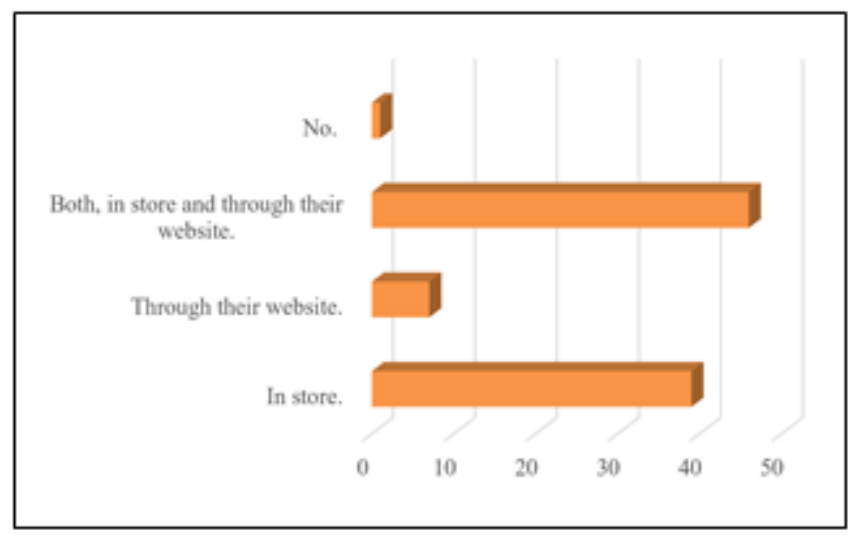

FIGURE I. EXAMPLE OF A FIGURE CAPTION.

The survey conducted provides authors with specific information on shopping habits and some trends in developing e-commerce examples in the European chain of China. The main findings of this survey can be summarized as follows: (1) on average, people make shopping once or twice a week because it allows to save time and effort. (2) Split between customers, who likes who is online and those who still prefer the traditional in-store shopping experience. (3) The main reason why some customers like to shop in the store is a tangible product. (4) The preference for online shopping and ecommerce use is generally convenient from time to time and location. (5) The general market still shows preference for traditional shopping. Although consumers with increasingly open e-commerce experiences are not yet ready to completely replace the "E" experience of in-store shopping. (6)The website's Wal-Mart and Carrefour reflect consumer preferences. The reason for the success of e-commerce for this company is undetermined, but one of the most common answers is the lack of knowledge about the site's capabilities. This provides important evidence for the customer's e-commerce training and the organization should think about the issue. (7)A top-featured e-commerce that attracts customers is user-friendly.

Two people based on this issue have never been shopping at large retail stores and have to be excluded from the sample. The age distribution shows that most of the current customers are between the ages of 26 and 55 (Figure 2):

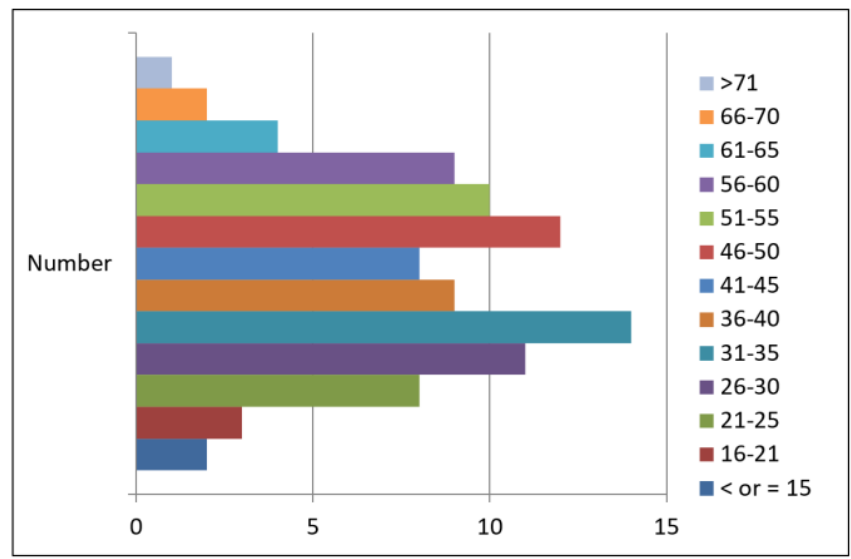

FIGURE II. AGE. 
Outcome surveys show that male and female respondents with relatively equal divisions are considered to be represented (Figure 3):

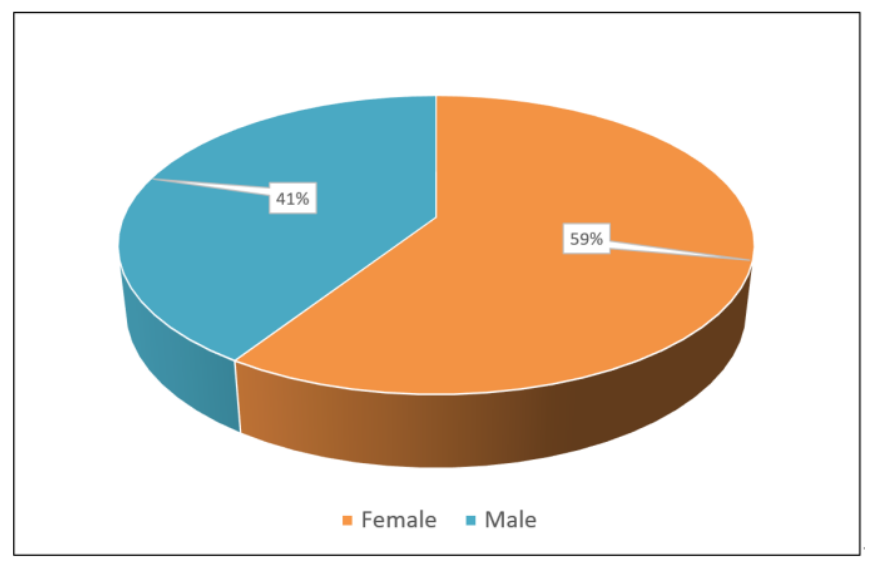

FIGURE III. GENDER.

The survey conducted provides authors with specific information on shopping habits and some trends in developing e-commerce examples in the European chain of China. The main findings of this survey can be summarized as follows: on average, people make shopping once or twice a week because it allows time and effort to be saved. Given that this result is a reasonable assumption, this will facilitate the frequency of shopping convenience and location links. The representatives of the results of the survey participated in the following table (Figure 4):

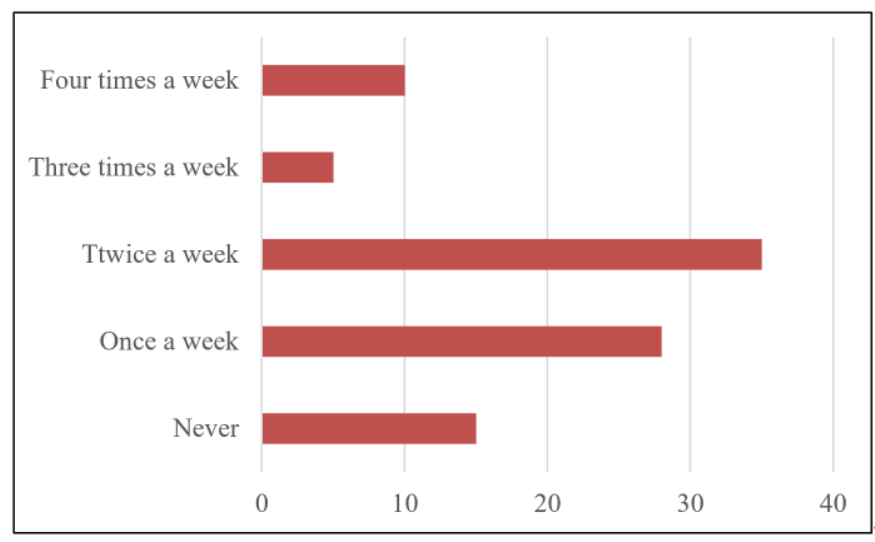

FIGURE IV. AVERAGE NUMBER OF PURCHASES TO RETAIL STORES?

The results of the above research provide an insight into the customer's preferences and main advantages of e-commerce, a more classic in-store shopping experience. The results did not counter the initial assumptions in the survey, but re-confirmed the link between the authors of the initial beliefs, with successful chain operations and e-commerce practices.

\section{CONCLUSION}

E-commerce and shackle management Although many companies have begun to try, most of them are still in the exploration stage, although they have some experience and experience (such as e-commerce proposed B2B2C mode), but the whole in terms of industry, there is still a "shackle management-e-commerce" application model that is general, comprehensive and worthy of extensive reference. This is the focus of this paper. At the same time, this paper also attempts to apply the application system from the overall framework to the specific function modules are designed and implemented to explore. Although the shackle operation has developed rapidly in recent years, the supporting systems of finance, law, distribution, and credit are still very incomplete, which restricts their development to a certain extent. Many shackle retail enterprises are still implementing the traditional management mode of integration, top management, and tertiary accounting. There is no central procurement system.

Each shackle shop is in power, and the advantages of shackle management are difficult to play. In addition, consumers still like to directly contact and feel the goods and services provided by supermarkets. In the short term, most people in the concept and habits have not generally accepted the way of online shopping. Moreover, the overall information level of the shackle enterprises at this stage is still not high, and the understanding of e-commerce is even more unfamiliar. At present, (M. J. Epstein2017), it is only necessary to strengthen the information construction of enterprises, establish and improve the enterprise information system, and explore the development direction and mode of appropriate situations. After the government-related system is gradually matured, the shackle business development enterprise has practical significance for consumers' B2C. Conversely, if a company invests blindly in e-commerce, it will inevitably lead to an increase in sales costs and a decrease in profits. Therefore, the shackle enterprises must rely on according to its own embarrassing situation, it develops e-commerce and explores the combination of e-commerce and shackle management. While absorbing the experience of domestic and foreign counterparts, it needs to be carried out on the basis of its own current situation and in line with future development trends.

\section{REFERENCES}

[1] N. Dholakia and W. Fritz, "Global E-Commerce and Internet Marketing: The Evolution of Watching", Arbitration Books, 2016.

[2] J. Saastamoinen, "Returning to Reputational Retail E-Commerce", ECommerce Research Journal, 2015.

[3] E.S. Harris and C. Vega, "What chain store sales tell us about consumer spending?”, Economic Policy Review, 2015.

[4] T.P. Hoffman "Wal-Mart in China: Challenge the supply chain of foreign retailers", China Business Review, 2016.

[5] L Exchange, "attacking the retail market in China", China Business Review. Volume: 22, 2017.

[6] M. J. Epstein, "Implementing E-Commerce Strategy: A Guide to Business Success" Dot.Com, 2017 